\title{
Immunization with plasmid DNA expressing Heat Shock Protein 40 confers prophylactic protection against chronic Toxoplasma gondii infection in Kunming mice
}

\author{
Zhong-Yuan $\mathrm{Li}^{1,2, *}$, Jing Lu ${ }^{2}$, Nian-Zhang Zhang ${ }^{2}$, Hany M. Elsheikha ${ }^{3}$, Jun-Ling Hou ${ }^{2}$, \\ Hai-Ting $\mathrm{Guo}^{2,4}$ and Xing-Quan $\mathrm{Zhu}^{2}$ \\ ${ }^{1}$ College of Animal Science and Technology, Anhui Agricultural University, Hefei, Anhui 230036, PR China \\ 2 State Key Laboratory of Veterinary Etiological Biology, Key Laboratory of Veterinary Parasitology of Gansu Province, Lanzhou \\ Veterinary Research Institute, Chinese Academy of Agricultural Sciences, Lanzhou, Gansu 730046, PR China \\ ${ }^{3}$ Faculty of Medicine and Health Sciences, School of Veterinary Medicine and Science, University of Nottingham, Sutton Bonington \\ Campus, Loughborough LE12 5RD, UK \\ ${ }^{4}$ College of Biological Science and Technology, Heilongjiang Bayi Agricultural University, Daqing, Heilongjiang 163319, PR China
}

Received 29 March 2018, Accepted 7 July 2018, Published online 23 July 2018

\begin{abstract}
Toxoplasma gondii causes one of the most common protozoal diseases of humans and animals worldwide. With the aim of designing an effective vaccine against $T$. gondii infection, we examined the immunogenicity of a DNA vaccine expressing heat shock protein 40 (HSP40) against challenge with T. gondii (type I RH and type II Pru) strains in Kunming mice. The plasmid pVAX1-HSP40 was constructed and used to immunize mice by intramuscular injection for three sequential immunizations with two-week intervals. This immunization regimen significantly reduced parasite cyst burden in pVAX1-HSP40-immunized mice $(1871.9 \pm 142.3)$ compared with control mouse groups immunized with pVAX1 $(3479.2 \pm 204.4)$, phosphate buffered saline $(3024.4 \pm 212.8)$, or left untreated $(3275.0 \pm 179.8)$ as healthy controls $(p<0.01)$. However, immunization failed to protect mice against challenge with the virulent RH strain. There was a significant increase in $\mathrm{T}$ lymphocyte subclasses $\left(\mathrm{CD} 3 \mathrm{e}^{+} \mathrm{CD} 4^{+} \mathrm{T}\right.$ and $\mathrm{CD} 3 \mathrm{e}^{+} \mathrm{CD} 8 \mathrm{a}^{+} \mathrm{T}$ lymphocytes) in splenic tissues in immunized mice compared with controls $(p<0.05)$. However, the level of antibodies, lymphocyte proliferation and concentration of cytokines (IFN- $\gamma$, IL-2, IL-4, IL-10 and IL-12p70) were not significantly different between immunized and control mouse groups $(p<0.05)$. These data indicate that pVAX1-HSP40 induced specific immune responses and achieved a significant reduction in the number of brain cysts in Pru-infected mice, and thus can be tested in future immunization studies along with plasmids containing other immunogenic proteins as a cocktail vaccine to fully abolish chronic toxoplasmosis.
\end{abstract}

Key words: Toxoplasma gondii, HSP40, DNA vaccine, Chronic infection, Immune evaluation.

Résumé - L'immunisation avec de l'ADN plasmidique exprimant la protéine de choc thermique HSP40 confère une protection prophylactique contre une infection chronique à Toxoplasma gondii chez des souris Kunming. Toxoplasma gondii provoque l'une des maladies à protozoaires les plus courantes chez les humains et les animaux dans le monde entier. Dans le but de concevoir un vaccin efficace contre l'infection à $T$. gondii, nous avons examiné l'immunogénicité d'un vaccin ADN exprimant la protéine de choc thermique HSP40 contre des souches de T. gondii (type I RH et type II Pru) chez des souris Kunming. Le plasmide pVAX1-HSP40 a été construit et utilisé pour immuniser des souris par injection intramusculaire pour trois immunisations séquentielles avec des intervalles de deux semaines. Ce schéma d'immunisation a réduit significativement la charge de kyste parasitaire chez les souris immunisées par pVAX1-HSP40 $(1871.9 \pm 142.3)$ par rapport aux groupes de souris témoins immunisés avec pVAX1 $(3479.2 \pm 204.4)$, traités par solution saline tamponnée au phosphate $(3024.4 \pm 212.8)$ ou non traités $(3275.0 \pm 179.8)$ comme témoins sains $(p<0.01)$. Cependant, l'immunisation n'a pas réussi à protéger les souris contre la souche virulente RH. Il y avait une augmentation significative des sousclasses de lymphocytes $\mathrm{T}$ (lymphocytes $\mathrm{T} \mathrm{CD} 3 \mathrm{e}^{+} \mathrm{CD} 4^{+} \mathrm{T}$ et $\mathrm{CD} 3 \mathrm{e}^{+} \mathrm{CD} 8 \mathrm{a}^{+}$) dans les tissus spléniques chez les souris immunisées par rapport aux témoins $(p<0.05)$. Cependant, le taux d'anticorps, la prolifération lymphocytaire et la concentration de cytokines (IFN- $\gamma$, IL-2, IL-4, IL-10 et IL-12p70) n'étaient pas significativement différents entre les groupes de souris immunisés et témoins $(p<0.05)$. Ces données indiquent que

\footnotetext{
*Corresponding author: 1zy210930@163.com
}

This is an Open Access article distributed under the terms of the Creative Commons Attribution License (http://creativecommons.org/licenses/by/4.0), which permits unrestricted use, distribution, and reproduction in any medium, provided the original work is properly cited. 
pVAX1-HSP40 induit des réponses immunitaires spécifiques et réduit significativement le nombre de kystes cérébraux chez les souris infectées par Pru, et peut donc être testé dans des études de vaccination futures avec des plasmides contenant d'autres protéines immunogènes dans un cocktail de vaccins, pour abolir la toxoplasmose chronique.

\section{Introduction}

The Apicomplexan protozoan Toxoplasma gondii is the agent of a major zoonotic disease, toxoplasmosis, affecting mainly immunocompromized individuals and naïve pregnant women [3, 5, 8, 29]. Current therapeutic medicines are not highly effective or cause adverse effects [1, 36]. Currently, there are no approved human vaccines against toxoplasmosis disease, and efforts are ongoing to identify protective antigens and the best strategies for vaccine development [17, 35, 39]. Effective therapeutic interventions are thus desirable and will be facilitated by a better understanding of the extent of the efficacy achieved by vaccination using key proteins to prevent T. gondii infection.

Heat shock proteins (HSPs) are ubiquitous constitutively or inducibly expressed proteins that act as molecular chaperones assisting in the assembly, folding, stabilization, and translocation of other cellular proteins. They are generally upregulated in response to various stress conditions [33], and bind unfolded, misfolded, or denatured proteins to prevent unwanted aggregation [32]. HSPs play roles in cell cycle progression, and transcriptional and posttranslational processes, such as protein folding, stability, transportation, and degradation, and they also play roles in the pathogenesis of inflammation and cancer $[20,27,37]$. HSPs are highly effective and versatile molecules in promoting immune responses against tumors and infections [7]. They can also mediate antigen presentation and activation of immune cells, such as lymphocytes, macrophages and dendritic cells [6]. They are presumed to have immunogenic properties due to their ability to bind, stabilize, and protect the antigen from degradation [34].

HSP40 plays a regulatory role in DNA duplication, protein modification, degradation and translocation across the membrane, endocytosis, and cell-signal transduction [15, 24]. It is involved in the pathogenicity of viruses such as Simian virus 40 [21] and protozoa such as Plasmodium falciparum [30]. HSP40 plays an essential role in the mechanisms of T. gondii bradyzoite development [9], and the nucleotide sequences of HSP40 genes are highly conserved among $T$. gondii genotypes, indicating that HSP40 might be a good vaccine candidate to counter the development and dissemination of T. gondii [23]. In this study, we tested the hypothesis that a DNA vaccine could provide a safe and reliable strategy against acute and chronic infection with $T$. gondii, and that HSP40 is a target of protective immune responses. Our results indicate that HSP40-based DNA vaccine effectively inhibited parasite cyst burden and induced antigen-specific adaptive cellular immune response.

\section{Materials and methods \\ Ethics statement}

All animal experiments were performed strictly in accordance with the guidelines of the Animal Ethics Procedures of the People's Republic of China. Ethical approval to conduct the procedures that involved mouse immunization and parasite challenge was obtained from the Animal Ethics and Administration Committee of Lanzhou Veterinary Research Institute, Chinese Academy of Agricultural Sciences (Approval No. LVRIAEC2012-011).

\section{Animals and parasites}

Female, 6-8-week old specific pathogen-free (SPF) grade, Kunming mice were purchased from the Laboratory Animal Center of Lanzhou Biological Product Institute (Lanzhou, China). Mice were housed in a High-density Touch Screen Mouse IVC System (FENGSHI, Qingdao, China), and their food and bedding materials were provided by Beijing Keao corporation (http://u6452366.b2bname.com/). Tachyzoites of T. gondii RH strain (Genotype I) maintained in vitro in African green monkey kidney cells and cysts of $T$. gondii Pru strain (Genotype II) separated from brain tissues of orally Pru-infected Kunming mice were used in the parasite challenge experiments to test the efficacy of the immunization. T. gondii lysate antigen (TLA) was prepared as described previously [22].

\section{Constructions of recombinant pET30a-HSP40 and pVAX1-HSP40 plasmids}

Total RNA was extracted from $T$. gondii RH tachyzoites using the E.Z.N.A. ${ }^{\circledR}$ Total RNA Kit I (Omega, Norcross, Georgia, USA). Based on the reference sequence of the ME49 strain (ToxoDB: TGME49_265310), a pair of specific primers (forward primer: $5^{\prime}$-GGGGTACCATGGGGAAGGACTACTACAGAA-3'; reverse primer: 5'-CGCGGATCCCTACACGTTCGGAAGCAGTT-3') was designed and used to amplify the coding sequence of the $T$. gondii HSP40 gene. The KpnI and BamHI restriction sites are underlined in the primers. RT-PCR was carried out following the instructions of the PrimeScript ${ }^{\circledR}$ One Step RT-PCR Kit (TaKaRa, Dalian, China). The amplification reaction was performed in the thermocycler with the following program: a reverse transcription reaction at $50{ }^{\circ} \mathrm{C}$ for $0.5 \mathrm{~h}$; then denaturation at $94{ }^{\circ} \mathrm{C}$ for $2 \mathrm{~min}$; followed by 35 cycles of denaturation at $94{ }^{\circ} \mathrm{C}$ for $1 \mathrm{~min}$, annealing at $56.6{ }^{\circ} \mathrm{C}$ for $30 \mathrm{~s}$, extension at $72{ }^{\circ} \mathrm{C}$ for $1.5 \mathrm{~min}$, and was ended with a final extension at $72.0^{\circ} \mathrm{C}$ for $10 \mathrm{~min}$. The PCR products were purified using the E.Z.N.A. ${ }^{\circledR}$ Gel Extraction Kit (Omega) and were inserted into the pMD18-T linear vector (TaKaRa), generating plasmid pMD-HSP40. The pMD-HSP40 plasmids were digested using the restriction enzymes $K p n \mathrm{I} /$ Bam HI in order to obtain the HSP40 fragment. Then, the pET30a $(+)$ or pVAX1 plasmids were digested using the same restriction enzymes, and the HSP40 fragment was ligated to them using T4 DNA ligase (TaKaRa), constructing the recombinant pET30a-HSP40 or pVAX1-HSP40 plasmids, respectively. The sequences of the inserts were confirmed by sequencing. The pET30a-HSP40 plasmid was used to prepare recombinant 
HSP40 protein (rHSP40). The concentration of pVAX1HSP40 was measured at $260 \mathrm{~nm}$ and $280 \mathrm{~nm}$ using a BioMate 3S spectrophotometer (Thermo, Waltham, Massachusetts, USA). The plasmid was adjusted to a final concentration of $1 \mu \mathrm{g} / \mu \mathrm{L}$.

\section{Preparation of rHSP40 protein}

The pET30a-HSP40 plasmid was constructed using the same method and primers used to construct the pVAX1HSP40 plasmid above. This pET30a-HSP40 plasmid was transfected into Escherichia coli BL21 competent cells by heat shock at $42{ }^{\circ} \mathrm{C}$ for $1.5 \mathrm{~min}$, and was induced to express the rHSP40 protein in vitro using isopropyl- $\beta$-D-thiogalactoside (IPTG, Promega, Fitchburg, Wisconsin, USA). The products with 6-His tag were purified by Ni-NTA His Bind ${ }^{\circledR}$ Resin (Novagen, Madison, Wisconsin, USA). The purified rHSP40 protein was used to coat the wells of the 96-well plates in the enzyme-linked immunosorbent assay (ELISA) to measure the concentrations of specific anti-rHSP40 antibodies.

\section{Transfection and expression of pVAX1-HSP40 in vitro}

To confirm whether the HSP40 protein can be expressed in eukaryotic cells, we used human embryonic kidney cells 293 (HEK293), indirect immunofluorescence and Western blotting analyses, as described previously [13]. HEK293 cells were seeded at a concentration of $2.5 \times 10^{5}$ cells/well into a six-well tissue culture plate until the cells reached $\geq 70 \%$ confluence. Transfection with pVAX1-HSP40 or empty pVAX1 (vector control) was performed with LipofectAMINE 2000 reagent (Invitrogen, Carlsbad, California, USA), as instructed by the manufacturer. Approximately $72 \mathrm{~h}$ posttransfection, the cells were fixed with $4 \%$ paraformaldehyde (PFA) for $30 \mathrm{~min}$, permeabilized with $0.1 \%$ Triton $\mathrm{X}-100$ for $30 \mathrm{~min}$, and incubated with goat anti-T. gondii serum (1:50 in PBS) and the Alexa Fluor ${ }^{\circledR}$ 488-AffiniPure donkey antigoat $\operatorname{IgG}(\mathrm{H}+\mathrm{L})$ diluted 1:1000 in PBS (Jackson Immuno Research Inc., West Grove, Pennsylvania, USA) was added and the samples were kept at ambient temperature in the dark for $60 \mathrm{~min}$. The fluorescent images were obtained using a Zeiss Axioplan 2 fluorescence microscope (Carl Zeiss, Oberkochen, Germany).

Next, $\sim 10^{7}$ cells (transfected with either pVAX1-HSP40 or pVAX1) were collected at $72 \mathrm{~h}$ post transfection, suspended into $200 \mu \mathrm{L}$ of SDS-PAGE loading buffer (Sangon, Shanghai, China) and incubated at $100{ }^{\circ} \mathrm{C}$ for $10 \mathrm{~min}$. The products were separated using 5\%-12\% gradient bis-tris gels (Sangon) and transferred to the nitrocellulose membrane (PALL, Port Washington, New York, USA) using a TRANS-BLOT ${ }^{\circledR}$ SD CELL (Bio-Rad, Hercules, California, USA). The membrane was blocked with 5\% non-fat milk in PBS and incubated with goat anti- $T$. gondii serum (1:50 in PBS), and subsequently with HRP-conjugated rabbit anti-goat $\operatorname{IgG}(\mathrm{H}+\mathrm{L})$ (Agrisera, Vännäs, Sweden) (1:5000 in PBS). A DAB-HRP Color Development Kit was used, following the manufacturer's instructions (CWBIO, Beijing, China).

\section{Immunization protocol}

Kunming mice were randomly allocated into four groups (42 mice per group) and intramuscularly (i.m.) immunized three times at a two-week interval. The experimental mouse groups included: Group I injected with $100 \mu \mathrm{L}$ of sterile phosphate-buffered saline (PBS; pH 7.4) containing $100 \mu \mathrm{g}$ pVAX1-HSP40; Group II injected with $100 \mu \mathrm{L}$ of PBS containing $100 \mu \mathrm{g}$ of the empty pVAX1 (vector control); Group III injected with $100 \mu \mathrm{L}$ of sterile PBS alone; and Group IV received no treatment and served as a healthy control. Spleen tissues collected aseptically from immunized and control mice ( $n=3$ mice per group) prior to the challenge were chopped with scissors into small pieces, and the splenic tissue fragments were pressed gently through a fine nylon mesh in order to prepare single cell suspensions.

\section{Efficacy of immunization against acute and chronic toxoplasmosis}

The aim of these experiments was to test the efficacy of immunization with pVAX1-HSP40 against acute and chronic infections in mice. First, we tested the efficacy against acute infection two weeks after the final/third immunization by intraperitoneal inoculation ( $n=15 \mathrm{mice} /$ group) with $10^{3}$ tachyzoites of a virulent $T$. gondii $\mathrm{RH}$ strain. The survival times of all challenged mice were recorded daily. Secondly, we evaluated the level of protection induced by pVAX1-HSP40 against chronic infection in mice ( $n=15 /$ group) challenged with 10 cysts of a mildly virulent cyst-forming Pru strain of $T$. gondii. Mice were euthanized at 30 days post-challenge and their brains were removed and individually homogenized in $1 \mathrm{~mL}$ of PBS. The parasite cyst burden in the brain tissues of the mice was determined by examining dilutions of DBL-stained brain homogenates using a Zeiss wide-field epifluorescence microscope with $10 \times$ objective, as previously described [12].

\section{Determination of T lymphocytes in spleen tissue}

Splenic single-cell suspensions prepared from all mice prior to the challenge were used to analyze $\mathrm{T}$ lymphocytes using flow cytometry, as previously described [22]. Briefly, $10^{5}$ viable cells counted using a hemocytometer and $0.04 \%$ trypan blue dye (Bio-Rad) were suspended in $100 \mu \mathrm{L}$ of $2 \%$ FBS in PBS solution and incubated with $0.45 \mu \mathrm{L}$ of FITC antimouse CD3e, $0.25 \mu \mathrm{L}$ of APC-eFluor780 anti-mouse CD4 or $0.25 \mu \mathrm{L}$ of Percp-cy5.5 anti-mouse CD8a (eBioscience, San Diego, California, USA) at $4{ }^{\circ} \mathrm{C}$ for $30 \mathrm{~min}$ in the dark. After two washes with $2 \mathrm{~mL}$ of PBS, the samples were re-suspended in $300 \mu \mathrm{L}$ of FACScan buffer $\left(0.1 \% \mathrm{NaN}_{3}, 1 \% \mathrm{BSA}\right)$ and $250 \mu \mathrm{L}$ of $2 \%$ PFA solution for optical measurement. The data from three independent experiments were obtained using the FACScan flow cytometer and SYSTEM II software (BD Bio-sciences, San Jose, California, USA).

\section{Antibody detection using ELISA}

Blood samples were collected from the ophthalmic veins of three mice per group to assess the level of specific 

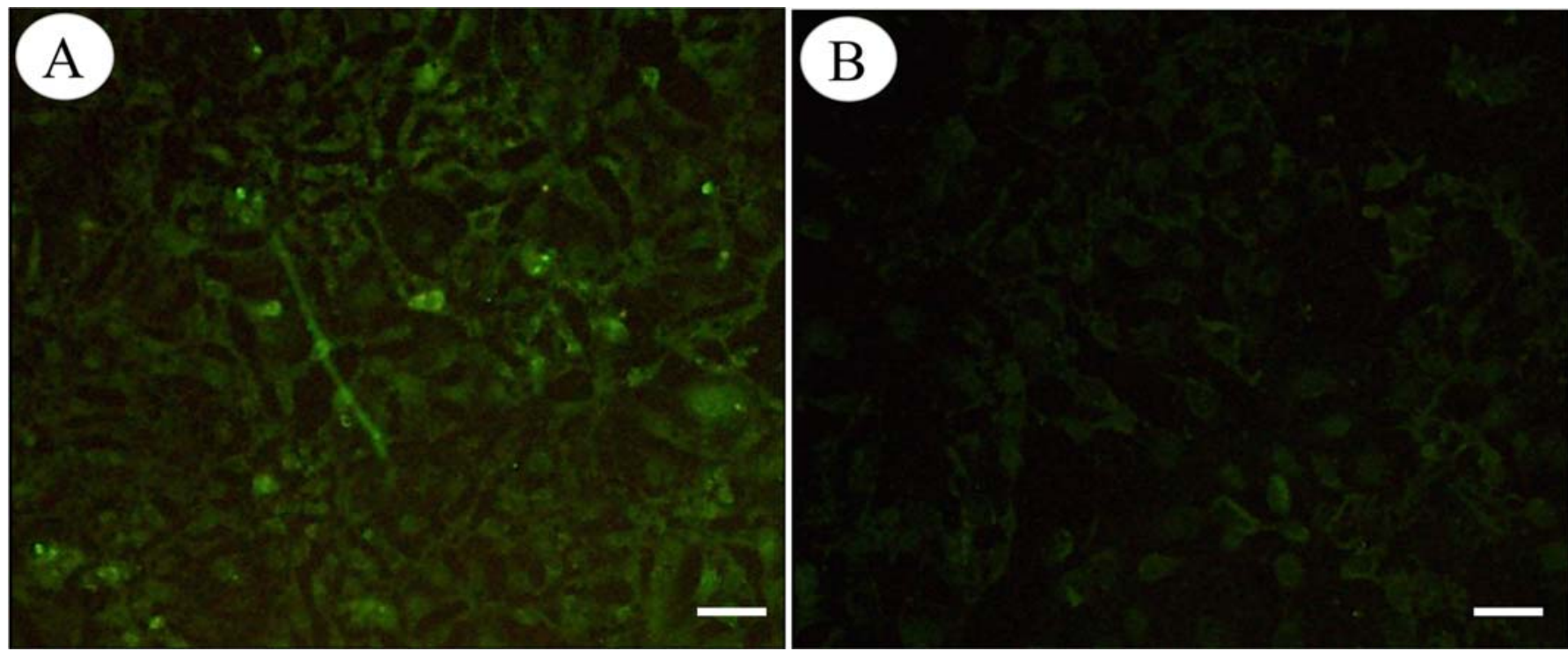

Figure 1. Immunofluorescence staining of HSP40 in HEK293 cells. HEK293 cells were transfected with pVAX1-HSP40 or pVAX1. At 72 h after transfection, the cells were fixed, permeabilized, and incubated with anti- $T$. gondii primary antibody. The cells were then incubated with fluorescein-conjugated secondary antibody and observed under a fluorescence microscope. The experiment was repeated three times, yielding similar results. The cells transfected with pVAX1-HSP40 showed the immunofluorescence of HSP40 proteins in the cytoplasm (A), whereas the cells transfected with the empty pVAX1 plasmid displayed little cellular immunofluorescence (B). Scale bar: $10 \mu \mathrm{m}$.

anti-anti-rHSP40 antibodies prior to each of the three immunization doses and prior to the challenge using ELISA. Flatbottom 96-well plates were coated overnight at $4{ }^{\circ} \mathrm{C}$ with $100 \mu \mathrm{L}$ of rHSP40 protein containing approximately $1 \mu \mathrm{g}$ of the protein per well. Test sera diluted at 1:10 were added to the wells and incubated for $1 \mathrm{~h}$ at $37^{\circ} \mathrm{C}$. The antibody measurement was carried out using SBA Clonotyping ${ }^{\mathrm{TM}}$ System/ HRP Kit (SouthernBiotech, Birmingham, Alabama, USA), according to the manufacturer's instructions (https://www. southernbiotech.com/techbul/5300-05.pdf). The optical density was measured using an ELISA reader (Bio-TekELx800, Winooski, Vermont, USA) at $405 \mathrm{~nm}\left(\mathrm{OD}_{405}\right)$. Each sample was tested in triplicate.

\section{Lymphocyte proliferation assay}

Splenic lymphocytes isolated from mice prior to challenge were cultured in 96-well plates at a concentration of $3 \times 10^{4}$ cells/well in $100 \mu \mathrm{L}$ RPMI 1640 medium containing $10 \%$ fetal bovine serum in the presence of $10 \mu \mathrm{g} / \mathrm{mL}$ of ultrasonic extracts of whole $T$. gondii tachyzoites (TLA) for $72 \mathrm{~h}$ at $37{ }^{\circ} \mathrm{C}$ in a $5 \% \mathrm{CO}_{2}$ incubator. Lymphocytes incubated in the absence of TLA extracts were used as nonstimulated controls. Lymphocyte proliferation was assessed using 3-(4,5-dimethylthiazol-2-yl)-5-(3-carboxymethoxyphenyl)-2-(4-sulfophenyl)-2H-tetrazolium, inner salt (MTS, $5 \mathrm{mg} / \mathrm{mL}$, Promega) (MTS) assay. Absorbance was measured at $490 \mathrm{~nm}$. The results were expressed as stimulation indices (SI), which were calculated as the ratio of $\mathrm{OD}_{490}$ values in vaccinated and control groups. The data represent three independent experiments.

\section{Measurement of cytokines}

To characterize the cytokine level profile in response to immunization and prior to the challenge, we determined the concentrations of IFN- $\gamma$, IL-2, IL-4, IL-10, and IL-12p70 in splenocyte culture supernatants using Legend $\mathrm{Max}^{\mathrm{TM}}$ ELISA Kits with Pre-coated Plates (Biolegend, San Diego, California, USA). Splenocytes obtained from immunized mice and their control counterparts at two weeks post final immunization were cultivated in 96-well plates. The splenocyte culture supernatants were collected at $24 \mathrm{~h}$ for the measurement of IL-2 and IL-4, at $72 \mathrm{~h}$ for the measurement of IL-10, and at $96 \mathrm{~h}$ for the measurement of IFN- $\gamma$ and IL-12p70. All samples were tested in triplicate.

\section{Statistical analysis}

All data were analyzed using the SPSS13.0 Data Editor (SPSS Inc., Chicago, Illinois, USA). Statistical differences among the four groups were determined by one-way analysis of variance (ANOVA) with the Tukey post hoc test. The differences in rates were analyzed by the student's $t$-test. Data are expressed as the mean \pm standard deviation $(S D)$. The level of significance was defined as $* p<0.05$ or $* * p<0.01$.

\section{Results}

\section{In vitro expression of pVAX1-HSP40}

The results of immunofluorescence staining showed immunofluorescence of HSP40 protein in the cytoplasm of pVAX1-HSP40-transfected HEK293 cells (Fig. 1A), whereas 


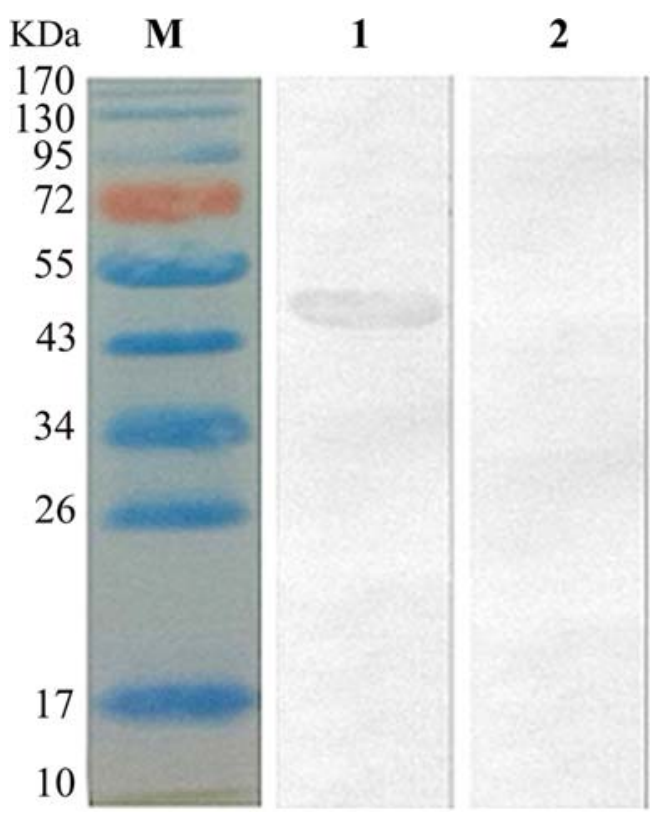

Figure 2. Western blotting of the expression of HSP40 protein encoded by the plasmid pVAX1-HSP40 in vitro. One band of approximately $46 \mathrm{kDa}$ was detected in the pVAX1-HSP40-transfected cells (Lane 1), whereas no band was detected in protein extract of cells transfected with the pVAX1 control (Lane 2). M: protein marker.

cells transfected with pVAX1 displayed little cellular immunofluorescence (Fig. 1B). Western blotting analysis showed a single band $(\sim 46 \mathrm{kDa})$ of the expected molecular size, indicating that pVAX1-HSP40 has been successfully expressed in eukaryotic HEK293 cells (Fig. 2). There was no protein band detected in the lysates of cells transfected with the empty pVAX1 vector.

\section{pVAX1-HSP40 protects mice against chronic infection}

After three booster immunizations using pVAX1-HSP40 with two-week intervals, Kunming mice were challenged with $10^{3}$ tachyzoites of $T$. gondii RH strain or 10 cysts of Pru strain in order to evaluate the protective efficacies against acute infection and chronic infection, respectively. The survival of immunized and non-immunized mice following challenge with $T$. gondii RH strain was monitored daily. As shown in Figure 3, no significant difference in the survival between pVAX1-HSP40-immunized mice $(6.93 \pm 1.28 \mathrm{~d})$ and mice in the non-immunized groups $(6.53 \pm 0.64 \mathrm{~d}$ for pVAX1, $6.40 \pm 0.63 \mathrm{~d}$ for PBS, and $6.33 \pm 0.62 \mathrm{~d}$ for healthy control) was detected $(p>0.05)$. Interestingly, pVAX1-HSP40 immunization achieved a significant reduction in the parasite cyst burden in the brain of pVAX1-HSP40-immunized mice $(1871.9 \pm 142.3)$ compared with that of mice in the control groups immunized with pVAX1 $(3479.2 \pm 204.4)$, PBS $(3024.4 \pm 212.8)$, and healthy control mice $(3275.0 \pm 179.8)$, achieving $53.8 \%, 61.8 \%$, and $57 \%$ reduction, respectively ( $p<0.01$; Fig. 4).

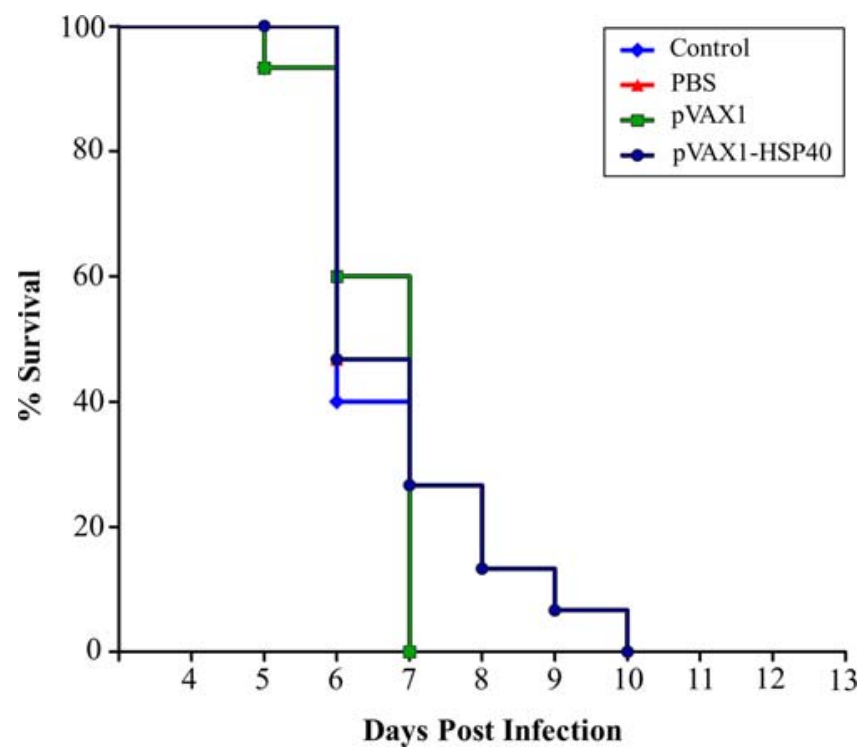

Figure 3. pVAX1-HSP40-based immunization failed to enhance the survival of acutely infected mice. Immunized and nonimmunized mice were intraperitoneally challenged with $1 \times 10^{3}$ tachyzoites of $T$. gondii RH strain at two weeks post the final immunization and their survival times were recorded daily until all mice died. No statistically significant difference was observed between control mouse groups $(p>0.05)$.

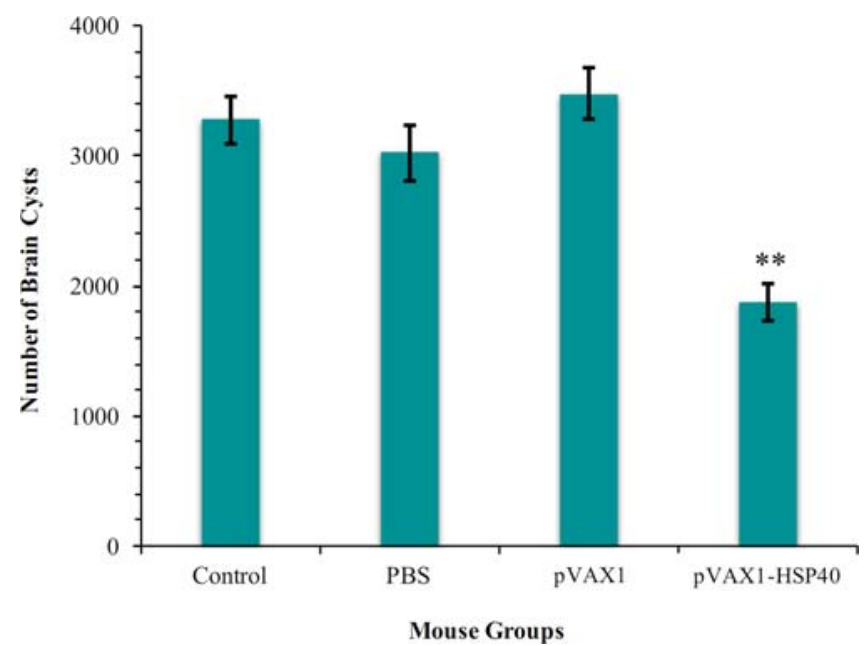

Figure 4. pVAX1-HSP40-based immunization protected against chronic infection. Number of brain cysts in mice challenged orally with 10 Pru cysts two weeks post the final immunization. The brain cysts in the pVAX1-HSP40-immunized mice were significantly lower compared with those in the control mouse groups $(* * p<0.01)$. No significant difference was detected between the control mouse groups $(p>0.05)$.

\section{Determination of $\mathbf{T}$ lymphocytes in spleen tissues}

The percentages of $\mathrm{CD} 3 \mathrm{e}^{+} \mathrm{CD} 4^{+} \mathrm{T}$ and $\mathrm{CD} 3 \mathrm{e}^{+} \mathrm{CD} 8 \mathrm{a}^{+} \mathrm{T}$ lymphocytes in spleen of immunized mice prior to challenge were determined using flow cytometry. We observed 


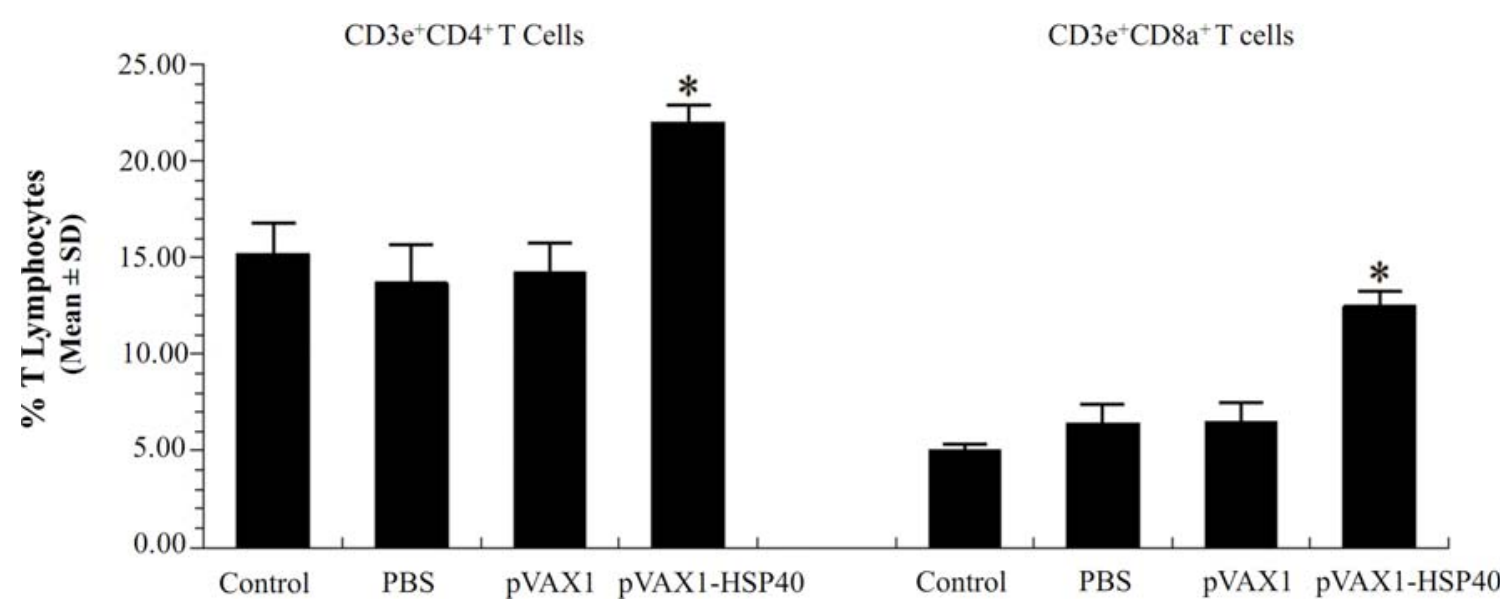

Figure 5. Flow Cytometry analysis of the proportion of $\mathrm{T}$ lymphocyte subclasses in mouse spleen. The $\mathrm{CD} 3 \mathrm{e}^{+} \mathrm{CD} 4^{+} \mathrm{T}-\mathrm{and} \mathrm{CD}_{\mathrm{e}} \mathrm{e}^{+} \mathrm{CD} 8 \mathrm{a}^{+} \mathrm{T}-$ lymphocytes in spleen of pVAX1-HSP40-immunized mice were increased significantly compared with that of mice in the control groups $(p<0.05)$. No significant difference was detected among the mice in the three control groups $(p>0.05)$.
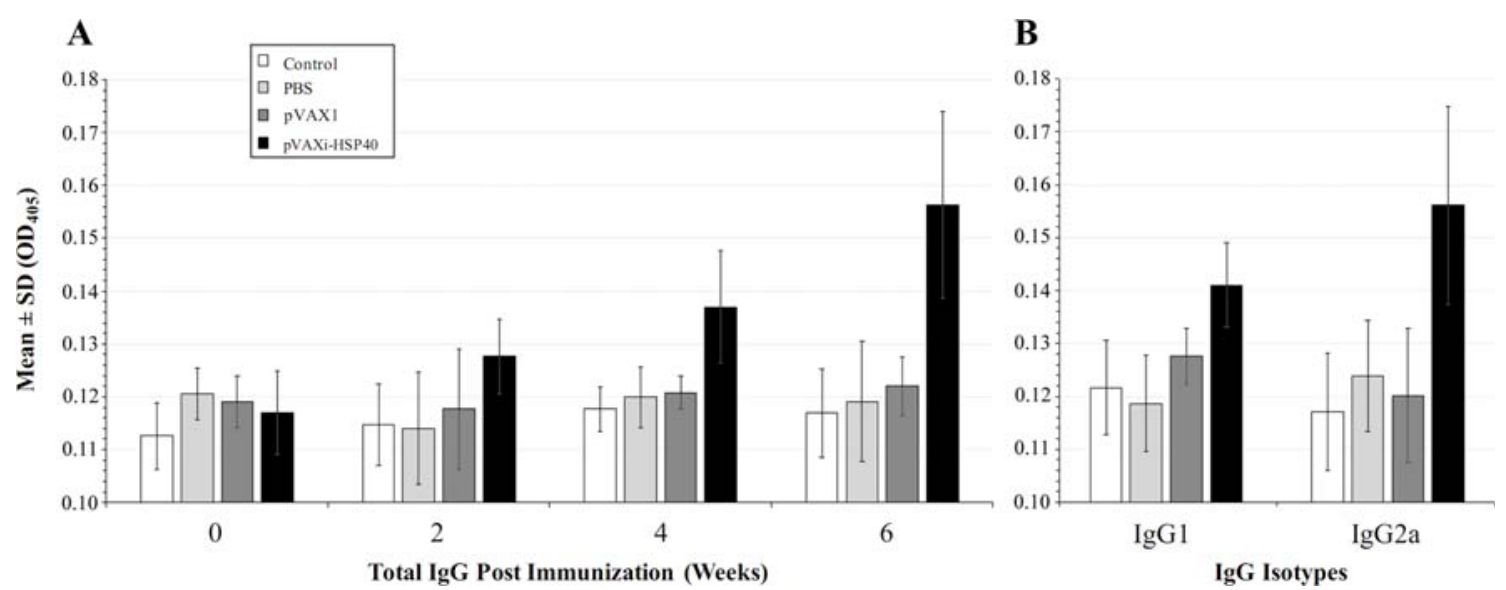

Figure 6. Levels of specific anti-rHSP40 antibodies in the serum of pVAX1-HSP40-immunized mice. (A) The optical densities $\left(\mathrm{OD}_{405}\right)$ of total IgG prior to each of the three booster immunizations at 0,2 and 4 weeks, and prior to the challenge at 6 week (i.e., two weeks after the third immunization) using ELISA. (B) Levels of IgG isotypes, IgG1 and IgG2a, two weeks after third immunization (i.e., 6 weeks after the primary immunization). There was no significant difference in the level of antibodies between immunized and control mice $(p>0.05)$.

significant increases in the percentages of $\mathrm{CD} 3 \mathrm{e}^{+} \mathrm{CD} 4^{+}$and $\mathrm{CD} 3 \mathrm{e}^{+} \mathrm{CD} 8 \mathrm{a}^{+} \mathrm{T}$ lymphocytes in pVAX1-HSP40-immunized mice $(22.0 \pm 0.86$ and $12.5 \pm 0.78$, respectively) compared with mice vaccinated with pVAX1 $(14.2 \pm 1.53$ and $6.5 \pm 0.98)$; with PBS (13.7 \pm 1.96 and $6.4 \pm 1.02)$ and in mice left non-immunized as healthy controls $(15.2 \pm 1.54$ and $5.0 \pm 0.33)(p<0.05$; Fig. 5).

\section{Measurement of specific antibodies in serum samples}

As shown in Figure 6A, the levels of specific antiT. gondii rHSP40 antibodies in the mouse sera examined prior to each of the three immunization doses, and prior to the challenge, were not significantly different between pVAX1HSP40-immunized mice and mice from the three control groups (pVAX1, PBS and healthy control) $(p>0.05)$. The levels of IgG1 and IgG2a were determined two weeks after the third immunization. One way ANOVA and Tukey's multiple comparisons test were used for statistical analysis of IgG1 and IgG2a data. The level of IgG2a was slightly increased in the pVAX1-HSP40-immunized mice compared with mice in all control groups, but the results was not statistically significant $(p>0.05$; Fig. 6B).

\section{pVAX1-HSP40 immunization did not induce lymphocyte proliferation}

The in vitro lymphocyte proliferation assay revealed that stimulation index of splenic lymphocytes from pVAX1HSP40-immunized mice was not significantly different $(p<0.05)$ when compared with that of non-immunized 


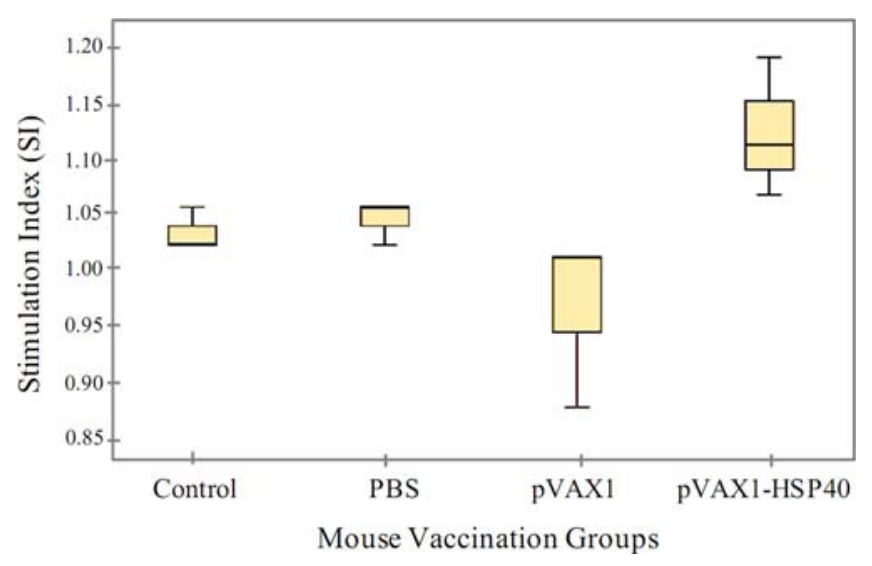

Figure 7. Lymphocyte proliferation assay. Splenocytes were obtained from immunized mice and the control groups prior to the challenge and cultivated in 96-well plates. Lymphocyte stimulation index was determined using the MTS assay. No significant difference was detected between pVAX1-HSP40-immunized group and control mice $(p>0.05)$.

controls, either in the presence of ConA or TLA (Fig. 7). This finding suggests a lack of induction of lymphocyte proliferation responses to TLA after vaccination with pVAX1-HSP40.

\section{Immunization did not influence the production of cytokines}

The concentrations of five cytokines (IFN- $\gamma$, IL-2, IL-4, IL-10, and IL-12p70) in splenic culture supernatants (Fig. 8) were not significantly different between immunized and control mice $(p>0.05)$.

\section{Discussion}

In the past few years, several attempts have been made to develop a preventative strategy to control $T$. gondii infection, such as using virulence-attenuated parasite strain and sub-unit vaccines $[2,17,18,35,39]$. Currently, leveraging the eukaryotic expression vector pVAX1 to develop DNA vaccine has been the focus of intense research because it can activate both innate and adaptive immune responses [41]. Interestingly, HSP40 has been associated with the virulence of a number of viruses and Apicomplexan protozoan parasites, and is consecutively expressed during the growth cycle of $T$. gondii, making it a good vaccine candidate $[4,21,30]$. For these reasons, the present study aimed to evaluate the protective efficacy of pVAX1 encoding HSP40 against $T$. gondii infection in mice.

The recombinant DNA plasmid pVAX1-HSP40 was successfully constructed and the expression of HSP40 in the transfected HEK293 cells was confirmed using an indirect immunofluorescent assay and Western blotting. This recombinant plasmid was used to immunize SPF-grade female Kunming mice for three sequential times with two-week intervals. pVAX1-HSP40-immunized mice developed fewer parasite cysts in their brain following oral challenge with 10 Pru cysts compared with non-immunized control mice. Specifically, pVAX1-HSP40 achieved 53.8\%, 61.8\% and 57\%

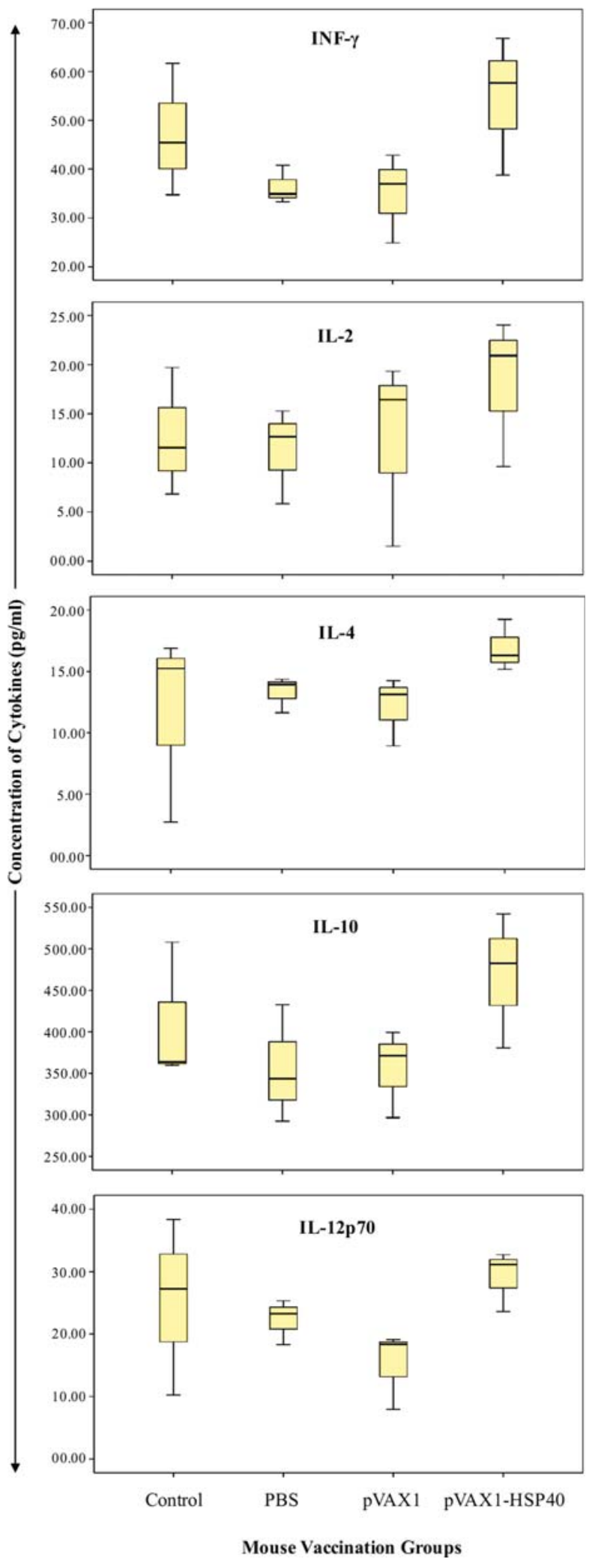

Figure 8. Levels of cytokines in splenocyte culture. Splenocytes were obtained from immunized and control mice prior to the challenge and cultivated in 96-well plates. The levels of IFN- $\gamma$, IL-2, IL-4, IL-10, and IL-12p70 cytokines in splenic culture supernatants were determined using ELISA. No significant difference was detected between pVAX1-HSP40-immunized mice and control mouse groups $(p>0.05)$. 
reduction in the parasite cyst burden, compared with cyst burden using vaccination with pVAX1, PBS, and healthy control, respectively. This result was higher than that obtained by DNA vaccine expressing T. gondii CDPK3 [40] and $39.08 \%$ by DNA plasmid (pVAX1-PF) encoding TgPF gene [13]. However, our result was comparable to the $57.8 \%$ reduction achieved by vaccination using multiple antigenic peptides encapsulated by chitosan microspheres [16].

In a striking contrast, the survival time of mice was not significantly different between mouse groups challenged with $\mathrm{RH}$ strain, indicating that sequential immunization with pVAX1-HSP40 was effective at preventing the chronic, but not acute infection with this parasite. Interestingly, the percentages of $\mathrm{CD} 3 \mathrm{e}^{+} \mathrm{CD} 4^{+} \mathrm{T}$ and $\mathrm{CD} 3 \mathrm{e}^{+} \mathrm{CD} 8 \mathrm{a}^{+} \mathrm{T}$ lymphocytes in the spleen of pVAX1-HSP40-immunized mice were significantly increased in comparison with control groups, which is consistent with previous studies [22, 38]. Both $\mathrm{CD}^{+}$and $\mathrm{CD}^{+} \mathrm{T}$ cells play an important role in resistance to $T$. gondii in mice $[14,26]$; this was also indicated by the susceptibility of individuals with $\mathrm{T}$ cell deficiencies to toxoplasmosis [25]. Thus, the significant activation of the subclasses of $\mathrm{T}$ lymphocytes in spleen of immunized mice may be a contributing factor to the observed reduction in parasite cysts in the brain of immunized mice challenged with $T$. gondii Pru strain.

Infection with $T$. gondii can trigger strong innate and adaptive immune responses in the infected hosts [10, 28]. Th1-type cellular immune response during $T$. gondii infection plays an important role in protecting hosts from acute infection $[11,31]$. Also, $\mathrm{CD}^{+}$cells and humoral antibody response contribute to controlling $T$. gondii during chronic infection by limiting development of the tissue cysts [19]. Therefore, specific anti- $T$. gondii antibodies including total $\operatorname{IgG}$ and its subclasses (IgG1 and IgG2a) were examined. Similar to other T. gondii virulence factors, such as rhoptry protein 18 [38], immunization with pVAX1-HSP40 was able to slightly increase the production of specific antibodies $(p>0.05)$ and only after the third booster immunization, indicating that the strategy of using multiple sequential doses was necessary to enhance the humoral immune response in the immunized mice. A mixed Th1/Th2 immune response, slightly skewed towards Th1-type response as indicated by a slightly higher $\operatorname{lgG} 2 \mathrm{a} /$ IgG1 ratio $(p>0.05)$, was detected in pVAX1-HSP40-immunized mice (Fig. 6B). This result suggests that vaccination using pVAX1-HSP40 can elicit a cell-mediated immune response, which was anticipated from a DNA vaccine. However, this finding was not supported by the results of the lymphocyte proliferation assay or the concentrations of cytokines (IFN- $\gamma$, IL-2, IL-4, IL-10, and IL-12p70), which were not significantly different between immunized and non-immunized mice.

In conclusion, sequential immunizations with pVAX1HSP40 induced cellular immune responses and reduced the number of brain cysts in mice challenged orally with Pru strain. However, immunization had no influence on lymphocyte proliferation or the levels of cytokines. These data suggest that $T$. gondii HSP40 may be a good DNA vaccine candidate, which can be used together with other parasite proteins to formulate a cocktail vaccine against chronic $T$. gondii infection.
Acknowledgements. Project support was provided, in part, by the Open Funds of the State Key Laboratory of Veterinary Etiological Biology (Grant No. SKLVEB2016KFKT015), the General Financial Grants of the Postdoctoral Science Foundation (Grant Nos. 2017M612056 and 2017B188), the Elite Program of the Chinese Academy of Agricultural Sciences, and the Agricultural Science and Technology Innovation Program (ASTIP) (Grant No. CAASASTIP-2016-LVRI-03).

\section{Conflict of interest statement}

The authors declare that they have no conflicts of interests in relation to this article.

\section{References}

1. Alday PH, Doggett JS. 2017. Drugs in development for toxoplasmosis: advances, challenges, and current status. Drug Design Development and Therapy, 11, 273-293.

2. Allahyari M, Mohit E. 2016. Peptide/protein vaccine delivery system based on PLGA particles. Human Vaccines \& Immunotherapeutics, 12(3), 806-828.

3. Ayoade F, Todd J, Al-Delfi F, King J. 2017. Extensive brain masses and cavitary lung lesions associated with toxoplasmosis and acquired immunodeficiency syndrome. International Journal of STD \& AIDS, 28(11), 1150-1154.

4. Behnke MS, Wootton JC, Lehmann MM, Radke JB, Lucas O, Nawas J, Sibley LD, White MW. 2010. Coordinated progression through two subtranscriptomes underlies the tachyzoite cycle of Toxoplasma gondii. PLoS One, 5(8), e12354.

5. Belluco S, Simonato G, Mancin M, Pietrobelli M, Ricci A. 2017. Toxoplasma gondii infection and food consumption: a systematic review and meta-analysis of case-controlled studies. Critical Reviews in Food Science and Nutrition, 11, 1-12.

6. Binder RJ. 2014. Functions of heat shock proteins in pathways of the innate and adaptive immune system. Journal of Immunology, 193(12), 5765-5771.

7. Binder RJ. 2008. Heat-shock protein-based vaccines for cancer and infectious disease. Expert Review of Vaccines, 7(3), 383-393.

8. Connolly MP, Goodwin E, Schey C, Zummo J. 2017. Toxoplasmic encephalitis relapse rates with pyrimethaminebased therapy: systematic review and meta-analysis. Pathogens and Global Health, 111(1), 31-44.

9. Coskun KA, Ozgür A, Otag B, Mungan M, Tutar Y. 2013. Heat shock protein 40-Gok1 isolation from Toxoplasma gondii $\mathrm{RH}$ strain. Protein and Peptide Letters, 20(12), 1294-1301.

10. Dupont CD, Christian DA, Hunter CA. 2012. Immune response and immunopathology during toxoplasmosis. Seminars in Immunopathology, 34(6), 793-813.

11. Fox BA, Sanders KL, Chen S, Bzik DJ. 2013. Targeting tumors with nonreplicating Toxoplasma gondii uracil auxotroph vaccines. Trends in Parasitology, 29(9), 431-437.

12. Fux B, Nawas J, Khan A, Gill DB, Su C, Sibley LD. 2007. Toxoplasma gondii strains defective in oral transmission are also defective in developmental stage differentiation. Infection and Immunity, 75(5), 2580-2590.

13. Gao Q, Zhang NZ, Zhang FK, Wang M, Hu LY, Zhu XQ. 2018. Immune response and protective effect against chronic Toxoplasma gondii infection induced by vaccination with a DNA vaccine encoding profilin. BMC Infectious Diseases, 18(1), 117. 
14. Gazzinelli RT, Hakim FT, Hieny S, Shearer GM, Sher A. 1991. Synergistic role of CD4 + and CD8 + T lymphocytes in IFNgamma production and protective immunity induced by an attenuated Toxoplasma gondii vaccine. Journal of Immunology, 146(1), 286-292.

15. Gorenberg EL, Chandra SS. 2017. The role of co-chaperones in synaptic proteostasis and neurodegenerative disease. Frontiers in Neuroscience, 11, 248.

16. Guo J, Sun X, Yin H, Wang T, Li Y, Zhou C, Zhou H, He S, Cong H. 2018. Chitosan microsphere used as an effective system to deliver a linked antigenic peptides vaccine protect mice against acute and chronic toxoplasmosis. Frontiers in Cellular and Infection Microbiology, 8, 163.

17. Hiszczyńska-Sawicka E, Gatkowska JM, Grzybowski MM, Długońska H. 2014. Veterinary vaccines against toxoplasmosis. Parasitology, 141(11), 1365-1378.

18. Jenkins MC. 2001. Advances and prospects for subunit vaccines against protozoa of veterinary importance. Veterinary Parasitology, 101(3-4), 291-310.

19. Johnson LL, Sayles PC. 2002. Deficient humoral responses underlie susceptibility to Toxoplasma gondii in CD4-deficient mice. Infection and Immunity, 70(1), 185-191.

20. Juwono J, Martinus RD. 2016. Does hsp60 provide a link between mitochondrial stress and inflammation in diabetes mellitus? Journal of Diabetes Research, 2016, 8017571.

21. Knox C, Luke GA, Blatch GL, Pesce ER. 2011. Heat shock protein 40 (Hsp40) plays a key role in the virus life cycle. Virus Research, 160(1-2), 15-24.

22. Li ZY, Chen J, Petersen E, Zhou DH, Huang SY, Song HQ, Zhu XQ. 2014. Synergy of mIL-21 and mIL-15 in enhancing DNA vaccine efficacy against acute and chronic Toxoplasma gondii infection in mice. Vaccine, 32(25), 3058-3065.

23. Li ZY, Lu J, Zhou DH, Chen J, Zhu XQ. 2015. Sequence variation in HSP40 gene among 16 Toxoplasma gondii isolates from different hosts and geographical locations. Biomed Research International, 2015, 209792.

24. Lianos GD, Alexiou GA, Mangano A, Mangano A, Rausei S, Boni L, Dionigi G, Roukos DH. 2015. The role of heat shock proteins in cancer. Cancer Letters, 360(2), 114-118.

25. Luft BJ, Remington JS. 1992. Toxoplasmic encephalitis in AIDS. Clinical Infectious Diseases, 15(2), 211-222.

26. Lütjen S, Soltek S, Virna S, Deckert M, Schlüter D. 2006. Organ- and disease-stage-specific regulation of Toxoplasma gondii-specific CD8-T-cell responses by CD4 T cells. Infection and Immunity, 74(10), 5790-5801.

27. Mattoo RU, Goloubinoff P. 2014. Molecular chaperones are nanomachines that catalytically unfold misfolded and alternatively folded proteins. Cellular and Molecular Life Sciences, 71(17), 3311-3325.
28. Montoya JG, Liesenfeld O. 2004. Toxoplasmosis. Lancet, 363(9425), 1965-1976.

29. Oz HS. 2017. Fetomaternal and pediatric toxoplasmosis. Journal of Pediatric Infectious Disease, 12(4), 202-208.

30. Petersen W, Külzer S, Engels S, Zhang Q, Ingmundson A, Rug M, Maier AG, Przyborski JM. 2016. J-dot targeting of an exported HSP40 in Plasmodium falciparum-infected erythrocytes. International Journal for Parasitology, 46(8), 519-525.

31. Pifer R, Yarovinsky F. 2011. Innate responses to Toxoplasma gondii in mice and humans. Trends in Parasitology, 27(9), 388-393.

32. Pockley AG. 2003. Heat shock proteins as regulators of the immune response. Lancet, 362(9382), 469-476.

33. Raggam RB, Salzer HJ, Marth E, Heiling B, Paulitsch AH, Buzina W. 2011. Molecular detection and characterisation of fungal heat shock protein 60. Mycoses, 54(5), e394-e399.

34. Srivastava P. 2002. Interaction of heat shock proteins with peptides and antigen presenting cells: chaperoning of the innate and adaptive immune responses. Annual Review of Immunology, 20, 395-425.

35. Wang JL, Elsheikha HM, Zhu WN, Chen K, Li TT, Yue DM, Zhang XX, Huang SY, Zhu XQ. 2017. Immunization with Toxoplasma gondii GRA17 deletion mutant induces partial protection and survival in challenged mice. Frontiers in Immunology, 8, 730.

36. Wei HX, Wei SS, Lindsay DS, Peng HJ. 2015. A systematic review and meta-analysis of the efficacy of anti-Toxoplasma gondii medicines in humans. PLoS One, 10(9), e0138204.

37. Wu J, Liu T, Rios Z, Mei Q, Lin X, Cao S. 2017. Heat shock proteins and cancer. Trends in Pharmacological Sciences, 38(3), 226-256.

38. Yuan ZG, Zhang XX, Lin RQ, Petersen E, He S, Yu M, He XH, Zhou DH, He Y, Li HX, Liao M, Zhu XQ. 2011. Protective effect against toxoplasmosis in mice induced by DNA immunization with gene encoding Toxoplasma gondii ROP18. Vaccine, 29(38), 6614-6619.

39. Zhang NZ, Chen J, Wang M, Petersen E, Zhu XQ. 2013. Vaccines against Toxoplasma gondii: new developments and perspectives. Expert Review of Vaccines, 12(11), 1287-1299.

40. Zhang NZ, Huang SY, Zhou DH, Chen J, Xu Y, Tian WP, Lu J, Zhu XQ. 2013. Protective immunity against Toxoplasma gondii induced by DNA immunization with the gene encoding a novel vaccine candidate: calcium-dependent protein kinase 3. BMC infectious diseases, 13, 512.

41. Zhang NZ, Wang M, Xu Y, Petersen E, Zhu XQ. 2015. Recent advances in developing vaccines against Toxoplasma gondii: an update. Expert Review of Vaccines, 14(12), 1609-1621.

Cite this article as: Li Z, Lu J, Zhang N, Elsheikha HM, Hou J, Guo H \& Zhu X. 2018. Immunization with plasmid DNA expressing Heat Shock Protein 40 confers prophylactic protection against chronic Toxoplasma gondii infection in Kunming mice. Parasite $25,37$. 
Reviews, articles and short notes may be submitted. Fields include, but are not limited to: general, medical and veterinary parasitology; morphology, including ultrastructure; parasite systematics, including entomology, acarology, helminthology and protistology, and molecular analyses; molecular biology and biochemistry; immunology of parasitic diseases; host-parasite relationships; ecology and life history of parasites; epidemiology; therapeutics; new diagnostic tools.

All papers in Parasite are published in English. Manuscripts should have a broad interest and must not have been published or submitted elsewhere. No limit is imposed on the length of manuscripts.

Parasite (open-access) continues Parasite (print and online editions, 1994-2012) and Annales de Parasitologie Humaine et Comparée (1923-1993) and is the official journal of the Société Française de Parasitologie. 